
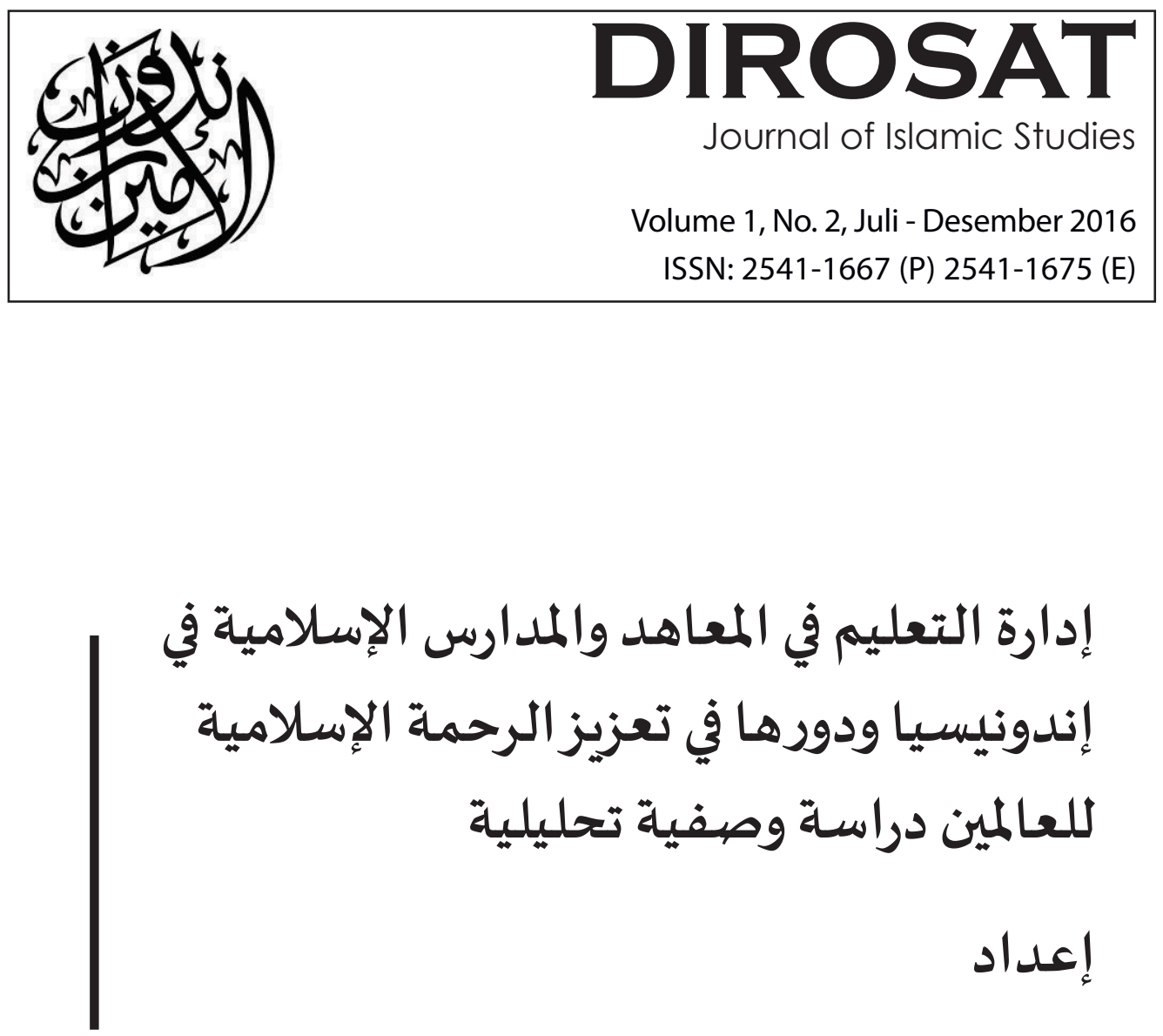

\title{
Burhanuddin
}

Ketua LPMSekolahTinggi Ilmu Ushuluddin DarulHikmah Bekasi

\section{Triyo Supriyatno}

Dekan Fakultas Tarbiyah UIN Maulana Malik Ibrahim Malang

Abstrak: Penelitian ini menegaskan bahwa pondok pesantren dan sekolah Islam di Indonesia, memiliki peran besar dalam menghadirkan perdamaian kehidupan, serta mengembalikan semangat sebagaimana yang terjadi pada awal sejarah Islam di Jawa abad ke-15 dan ke-16, yang diprakarsai oleh Syekh Maulana Malik Ibrahim (Tahun 1419 M di Jawa Timur). Dalam fokus penelitian ini, menunjukkan bahwa pondok pesantren merupakan lembaga sosial yang mampu berinteraksi dalam perubahan sosial dan politik, di dalamnya juga terdapat pengajaran dan pendidikan. Selain itu, juga dibahas tentang hal yang berkaitan dengan respon pondok pesantren dan sekolah Islam di Indonesia, 
dalam menghadapi era keterbukaan pasar bebas di tingkat ASEAN. Dalam hal ini, perlu sikap moderat, langkah antisipatif dalam hal ekonomi global, serta mampu mengambil posisi dalam isu-isu yang berkembang dalam kehidupan masyarakat, mampu mandiri serta berani melakukan penolakan dan protes. Peran pondok pesantren dan sekolah Islam, dalam menyampaikan pesan perdamaian di dunia, harus mengedepankan kebenaran, serta selalu mendidik manusia, serta membimbing mereka ke jalan yang benar. Itu semua merupakan bentuk antisipasi dari segala gangguan, hawa nafsu dan kejahatan, serta menolak segala hal yang syubhat. Itu semua merupakan solusi atas semua masalah tersebut, menjadi nasihat di dalamnya, serta bisa mengarahkan kepada jalan keselamatan.

Kata Kunci: Pembelajaran, Pondok dan Sekolah Islam Indonesia

\section{ملخص البحث}

هذا البحث يؤكد على أن للمعاهد والمدارس الإسلامية في إندونيسيا دورا كبيرا في تعزيز الرحمة الإسلامية للعالمين، وترجع نشأتها وتطورها إلى القرن الخامس عشر والسادس عشر الميلادي في جاوة، على يد الشيخ مولانا مالك إبراهيم ( ت: 19اعا م في جاوة الشرقية)،وفي هذا السياق يبين البحث أن المعهد يمثل مؤسسة اجتماعية تتفاعل في عملية التغير الاجتماعي والسياسي،مشيرا إلى أن هنالك من أهمالآخذ والإشكالياتالتيتعاني إدارة التعليم والتربية في المعاهد في إندونيسيا ونجد ذلكفيقصورالمناهجالتعليمية،وغيابالتخطيطوالتنسيقفيالتدريبالكهنيوالتقنيفيالتعليمينال نظامي واللانظامي، وغيابالجودةالنوعيةفيالتعليم. كما يتطرق البحث إلى ذكر مواقف المعاهد والمدارس الإسلامية في إندونيسيا من عصر انفتاح سوق الحرة على مستوى الآسيان: الموقف الوسطي، والموقف المنغلق عن المحارسات الاقتصادية والانشغالات الدنيوية، والموقف الذي يبعد عن القضايا التي قـسّ واقع حياة المجتمع، والموقف الذي يحمل خطاب الرفض والاحتجاج، وأبان هذا البحث وظيفة المعاهد والمدارس الإسلامية ودورها في تعزيز الرحمة نحو السلام العاليويشمل ذلك البيان التأصيلي وذلك بعرض الحق، وتعليم الناس السنة وهدايتهم إلى الصراط المستقيم. والبيان التحصيني وذلك 
بالتحذير من الانحرافات والأهواء والضلالات، ورد الشبهات. والبيان العلاجي وذلك بعالجة ما وقع من مشكلات، والإفتاء فيها، وبيان سبل الخلاص منها.

الكلمات المهمة: التعليم, المعاهد و المدارس في إندونيسيا

مقدمة

يعتبر المعهد الإسلامي في إندونيسيا من أبرز نوعية مؤسسات تعليمية إسلامية

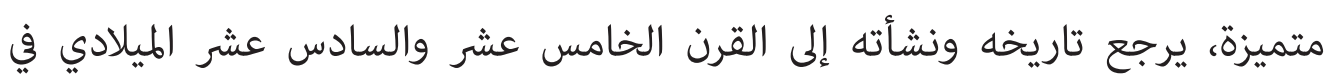

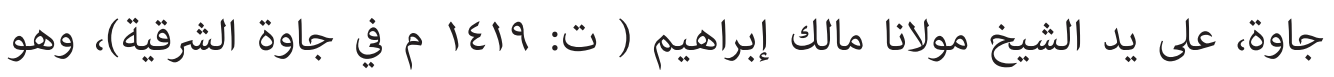

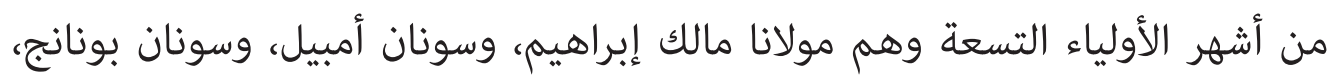
وسونان كاليجاغا، وسونان دراجات، وسونان غيري، وسونان قدوس، وسونان موريا،

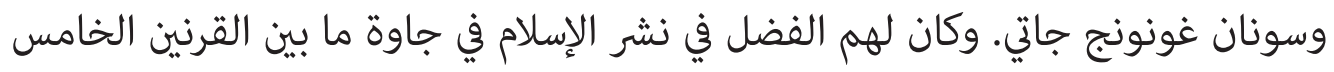

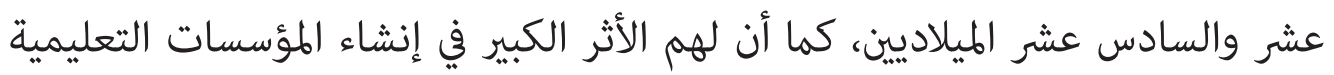

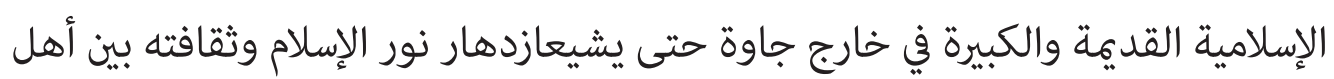
البلد شرقا وغربا. وبعد قرن واحد من عهد هؤلاء الأولياء التسعة وهو عصر سلطان

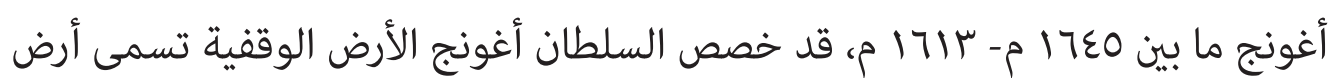

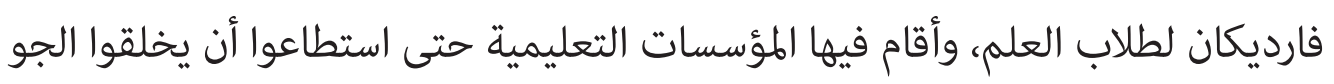

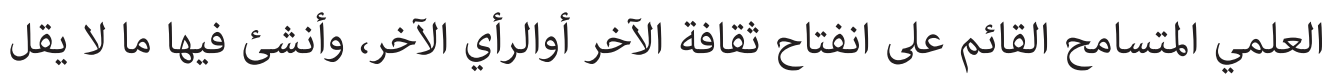

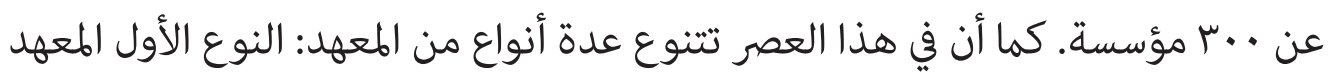

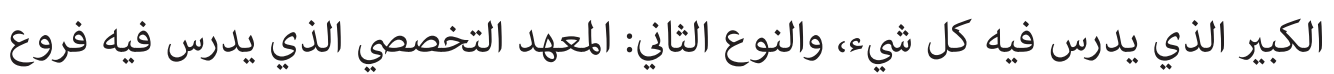

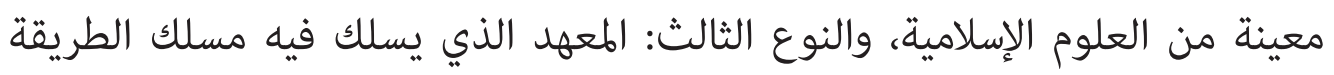
الصوفية. ولهذا قد وصل قمة تطوره في جاوة قبل القرن التاسع عشر الميلادي. 
276 - 292 | Burhanuddin \& Triyo Supriyatno, إدارة التعليم في المعاهد والمدارس الإسلامية

وإذا كانت إندونيسيا قد شهدت تلك الأوضاع السياسية المختلفة، وبخاصة في القرن الثامن عشر الميلادي'، فإن الناحية العلمية التابعة للمعاهد في ذلك الوقت مل تكن كذلك، فالعلوم بدأت تأخذ طريقها في التقدم والازدهار. وقد ظهر ذلك على يد المؤسسات الدينية التقليدية التي بدأت تبدي اهتماما كبيرا بطباعة الكتب ونشرها، ثم ازدادت المؤسسات التقليدية التي تولت القيام بهذا الدور كله ـ ونشرت في فترة وجيزة ما يقرب من خمسمائة عنوان، وقامت بتوزيعها على مختلف المعاهد في تلك الآونة، وأن ما يقرب من 0. ٪ ( خمسين في الهائة ) قام بتأليفها علماء إندونيسيا باللغات العربية والملايوية والإقليمية واللهجات، وخاصة في جزيرة جاوة التي تعدّ محور التربية التقليدية لكثرة المعاهد التقليدية بها إلى جانب بقية المدن ‘ ومن يقرأ بحث ( فانْ دِينْ

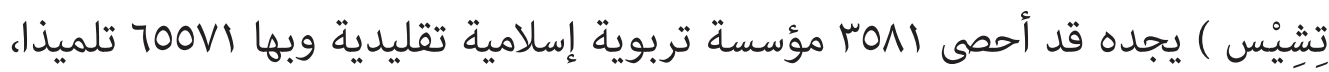
في حين يقول: فان دين بَرَجْ هناك اعهبو مؤسسة تربوية تقليدية بين جاوة ومَادُوْرَا ماعدا سلطنة جُوكْجَاكَرْتَا، ويبلغ عدد التلاميذ بهاتين المؤسستين (TVYTY ) تلميذا وهذا يدل على مدى العناية والاهتمام بالتعليمّ؛

وقد ذهب المؤرخ البروفيسور محمد يونس إلى أن نظام التعليم الإسلامي في عهد سلطان أغونج في جاوة يتضح ذلك كما يلي: ا. المعهد التخصصي هو الذي يدرس فيه بفهم عميق من علم معين من العلوم الإسلامية، ويدرس فيه أيضا الطرق الصوفية مثل القادرية والنقشبندية والشاطرية، وهذا المعهد يناسبه من يجلس في المستوى الأعلى. r. حلقات لتعليم القرآن الكريم في أماكن مختلفة للأطفال ابتداء من السن السابع. والهدف هوتعليم المتعلم حتى يتمكن من قراءة القرآن الكريم

| Iاتضح الأمر بأن عصره كان يشهد فسادا واضطرابا وتفككا وضياعا.

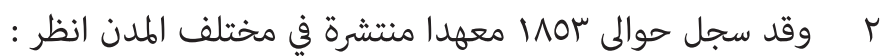
Muhammad Quraish Shihab Dkk, Studi Islamika Indonesien Journal For Islamic, Volume 2, P. 92, Thn 1995 M .

3 Zamakhsyari Dhofier, Tradisi Pesantren P. 35-37, PT. LP3ES Jakarta Thn 1985 M. 
وختمه، وهذه الحلقات يناسبها من يدرس في المستوى الابتدائي. س. المعهد الكبير والعام والكواد الدراسية فيه الفقه والتفسير والحديث والتوحيد والتصوف وعلم النجوم والنحو والصرف والتراكيب اللغوية، وهو يناسبه من يدرس في المستوى العالي. ع. المعهد المحلي الذي يدرس فيه مثل الكتب الأساسية الفقهية مع التركيز على كئ المذهب الشافعي كتدريس كتاب فتح القريب والأسس الأخلاقية من كتاب إحياء علوم الدين للإمام الغزالي، وهذا المعهد يناسبه من يدرس في المستوى المتوسط.

\section{المبحث الأول: الإدارة التعليمية للمعهد الإسلامي في إندونيسيا}

قد سبقت الإشارة السالفة الذكر بأن المعهد يمثل مؤسسة تعليمية إسلامية، ويتمتع أيضا بامتداد جذوره عميقة في أوساط المجتمع الإندونسي المسلم. وبفضل جهود شيوخ المعهد وأساتذته وعلمائه كان لهذه المؤسسات التعليمية الإسلامية في إندونيسيا الدور الريادي في أسلمة الهجتمع المسلم الإندونيسي وسرعة انتشار الإسلام في إندونيسيا.

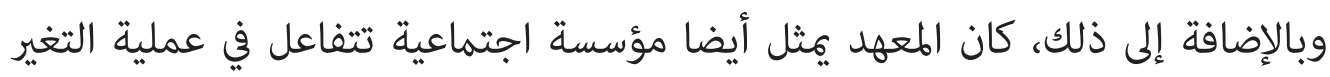
الاجتماعي والسياسي، الأمر الذي يجعله قادرا على الثبات والتطور مسايرا ومواكبا لمختلف التغيرات الاجتماعية، وذلك بثلاث دوافع:

الدافع الأول: هو شيخ المعهد الذي يمثل قدوة المجتمع بأسره، إذ أن نفوذه مل يقتصر في ذلك على تنوير الجانب الروحي فحسب، بل يتعدى إلى الجانب الاجتماعي والسياسي والثقافي مما مكنه أن يقوم بدوره في الوقت نفسه الوساطة الثقافية في عملية

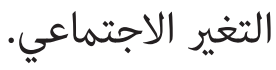

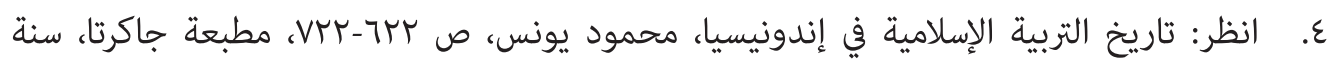


278 - 292 Burhanuddin \& Triyo Supriyatno, إدارة التعليم في المعاهد والمدارس الإسلامية

الدافع الثاني: ارتباط المعهد بالهجتمع ارتباطا وثيقا، ذلك لأن المجتمع نفسه هو الذي يقوم بإنشائه وتطويره، وبذلك يتمتع بنوع من الحرية.

الدافع الثالث: النظام التعليمي الذي يخرج كوادر يتمتع بالحرية والاستقلالية، إذ

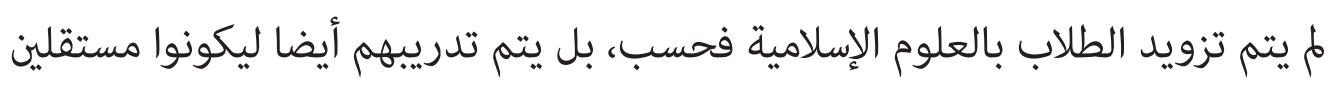
ومحركي المجتمع، ولذلك بدأت المعاهد في أعمالها تشترك في مختلف المشاريع التنموية المستدامة، ومنها تنظيم النسل والارتقاء باقتصاد المجتمعات القروية. وتعتبر هذه المشاريع ناجحة إلى حد ما، ومن ثم تحول كثير من هذه المعاهد إلى إنشاء مدارس عامة، ووحدات اقتصادية وأسرة منتجة.

لقد شهدت المعاهد الإسلامية في إندونيسيا منذ القرون الثلاثة الأخيرة من تطورات وتغيرات مثيرة. وفي ضوء هذا، فقد توصل مركز البحوث الإسلامية والاجتماعية في البحث الذي أجراه سنة $199 V$ م إلى وجود ثلاثة فاذج من نظام المعاهد الإسلامية في إندونيسيا، ويكن وصفه كالنحو التالي:

أولا: المعاهد الإسلامية كمؤسسة للتفقه في الدين وهي أن نظام المعهد في هذا السياق يقوم على نشر التعاليم الإسلامية والمحافظة على التراث وتطويره. ويلتزم هذا النوع من المعاهد بالنظام التقليدي القديم، فلا يقبل النظام التعليم العام، فيصعب عليه أن يصير شريك الحكومة في تطبيق المشاريع التنموية والاجتماعية. وعلى سبيل

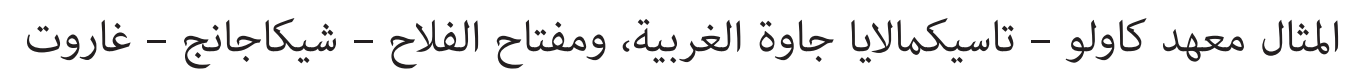
جاوة الغربية، بيد أن معهد الحسنة فقد نشأ وترعرع وسط مجتمع ساد فيه إنتاج النسيج والتطرير، ومع أن مصادر قويله من هذا الإنتاج، فإن المعهد إذ نصب نفسه كمؤسسة للتعليم الديني، فقد نهى تلاميذه عن المشاركة في التجارة أو العمل في المصنع، فالأنشطة الاقتصادية لم يكن ضمن البرامج التعليمية والتربوية للمعهد. ثانيا: نظام المعهد الذي يلعب دور الحركة الاقتصادية والاجتماعية والثقافية والدينية، وهو أن المعهد يقوم بأداء رسالته ورؤيته في التعليم الديني، مع دمج القيام 
بحركة اقتصادية دينية، ولم تخصص دراسة الكتب التراثية في هذا النوع من المعاهد إلا

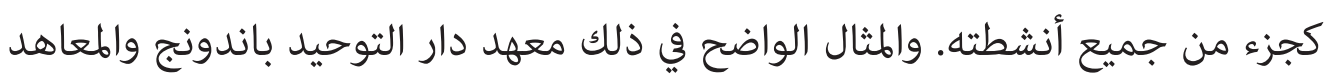

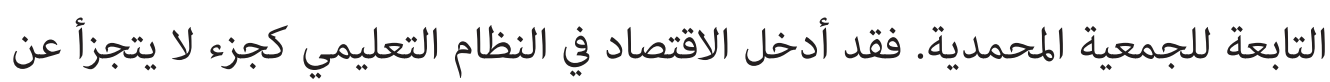

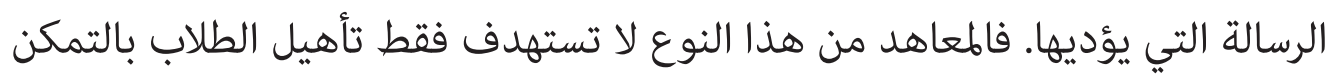

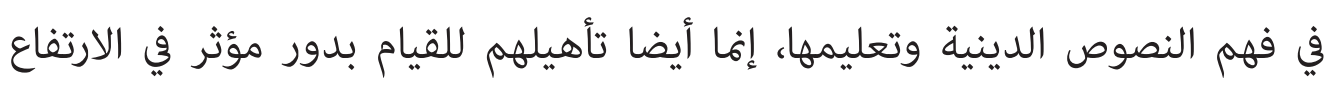

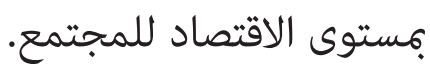

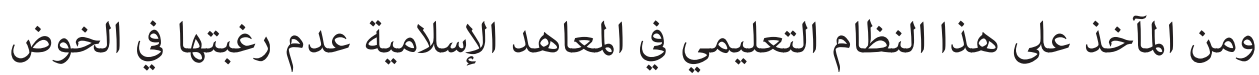

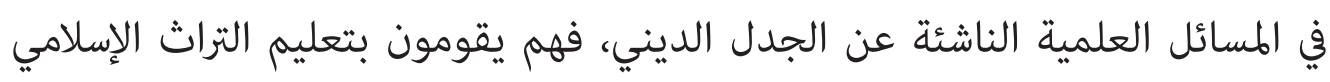

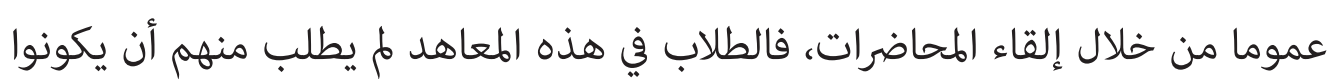

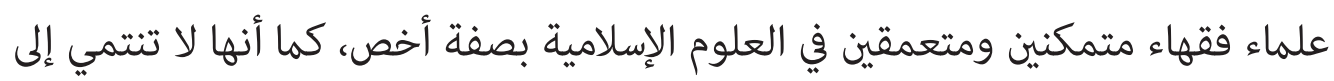

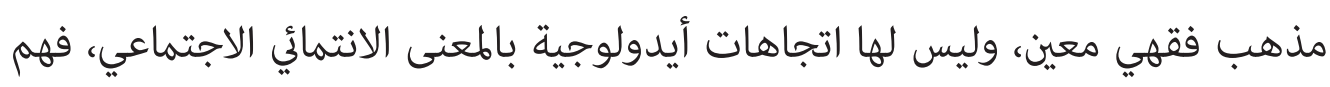

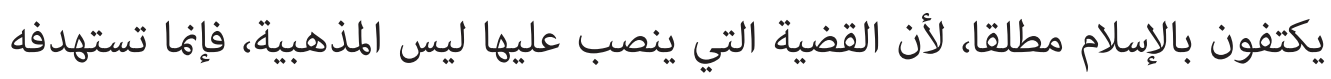

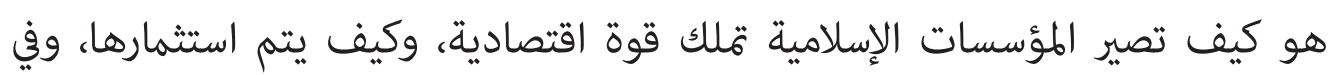

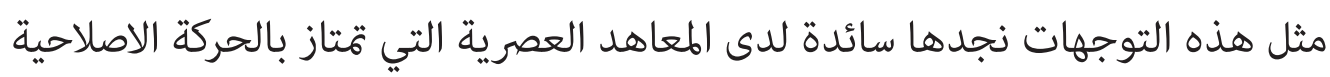

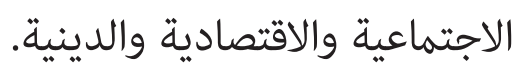

وهنالك من أهمالآخذ والإشكالياتالتيتعاني إدارة التعليم والتربية في المعاهد في إن

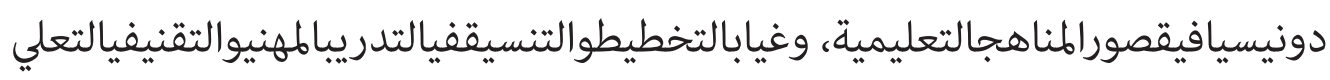

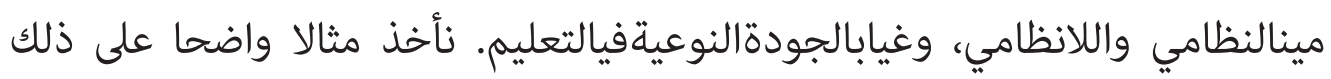
أن من أهممظاهر قصور المناهج والإدارة التعليمية في المعاهد الإسلامية في إندونيسيا

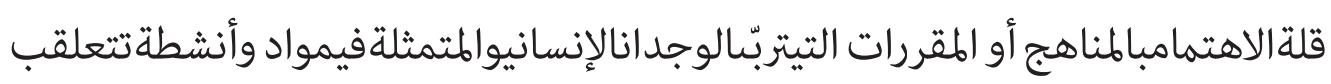
الفنون،وضعفالاهتمامبمقرراتالتربيةالبدنية،والعلومالصحية، والدروسالتيتتعلقبالمهارسا تالعمليةوالاندماجفيالحياةالواقعية،واملهاراتالتيتتطلبها الحياةاليومية،حيث إن تدريسها بطريقة لاتسهمفيتكوينذهنية ناقدةومقارنةومحللة،ومحدودية المقرراتالتيتهتم بالتوعية

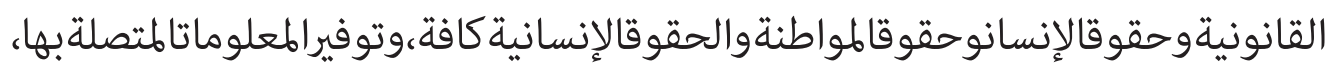


280 - 292 Burhanuddin \& Triyo Supriyatno, إدارة التعليم في المعاهد والمدارس الإسلامية

وضعفالاهتمام بتربيةالأطفالاموهوبينكمّا ونوعا،سواءفيالتعليمالأساسيأوالتعليمالثانوي ،أوالتعليمالعالي،رغمأنهذهالشريحةمن الطلابهممستقبلالأمةووسيلتهاإلمالتطوروالارتقا عالحضاري.

ومنالمسلّمبهأنتّنميطالمناهجواعتمادهاعلسالمدرّمحورأساسيافينقلاكعرفةينعكسس لباعلالعملية التعليميةالتي تيلإلتتغليبالطرائقالقائمةعلالتلقينوتنميةملكاتالحفظعلتح سابالهاراتالتحليلية وملكاتالنقدوالتفكيرالتفاعلي بمالايساعدعلتنميةالقدرةعلالتكيّفم عالمتغيّراتوالعملالجماعيالتييطلبها العملفيالقطاعالخاص. أمّالسبب فيكمنفيعدمتوفرم درّسينمنذويالخبرة العاليةبالقدرالكافيفيالاختصاصاتالدقيقة، فضلاعنالاكتظاظالذيتعانيم نه المؤسساتالتربويةوالجامعية. ثالثا: التقريب بين النظامين السابقين

وهو أن المعهد ليس مجرد مؤسسة لتأهيل الطلاب ليكونوا علماء متمكنين في العلوم الإسلامية فحسب، بل يدركون بالأمور الاجتماعية والههنية. ومن هنا أتيح لهم فرصة للتأهيل المهني سواء من خلال الأنشطة الاقتصادية التابعة للمعهد أم الاشتراك في الدورات التدريبية المهنية مثل الورشة أو الزراعة أو الشركات التعاونية وغيرها. ولذلك هنيك يتمتع المعهد بهذا النظام بالتفتح على محاولة تجديد التربية الإسلامية.

المبحث الثاني: إدارة المدارس الإسلامية التابعة لوزارة الشؤون الدينية كمدارس

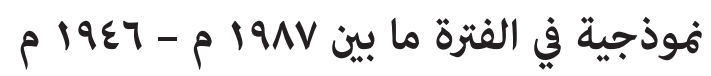
إن إدارة التعليم الإسلامي في عهد الاستعمار الهولندي تدرج تحت إدارة وزارتين وهما وزارة الرقابة الإدارية لموظفي الدولة لشؤون التعليم الإسلامي في المدارس العامة الحكومية، ووزارة الداخلية لشؤون التعليم الإسلامي في المدارس والمعاهد التابعة للمؤسسات والجمعيات الإسلامية. 
وفي تاريخ بّ يناير عام 19 أم، فقد أنشئت وزارة الشؤون الدينية، بناء على قرار

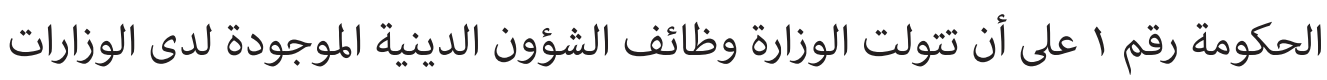

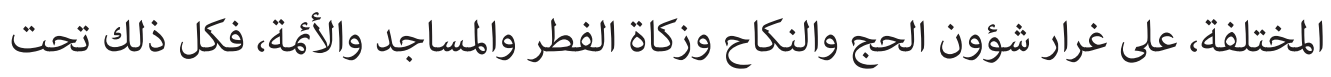

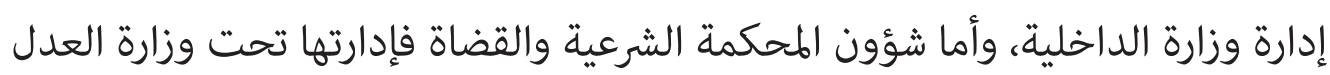
والهئية الاستشارية لشؤون المواطنين المسلمين. والناظر إلى تطور المدارس الإسلامية التابعة لوزارة الشؤون الدينية يجد ذلك من خلال ثلاث نوعيات من هذه المدارس وهي كالنحو الآتي: أولا: المدارس الإسلامية الحكومية

فقد أفادت اللائحة القانونية التي أصدرها وزير الشؤون الدينية رقم ا تاريخ 19

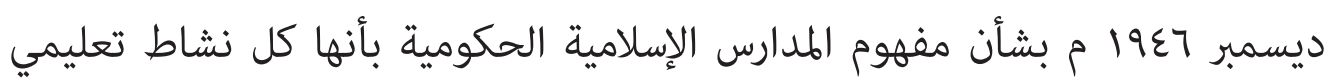

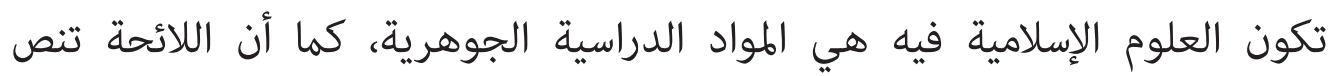

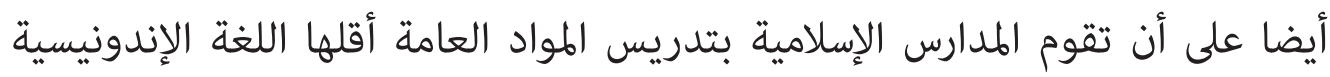

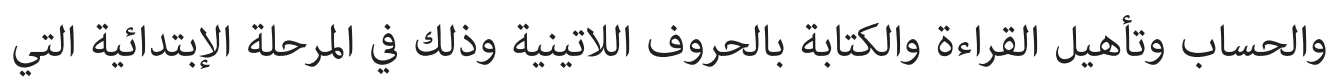

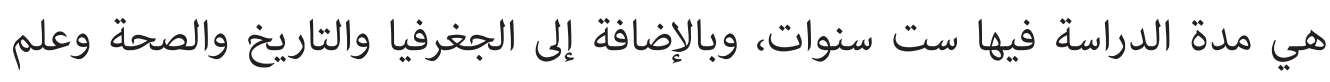

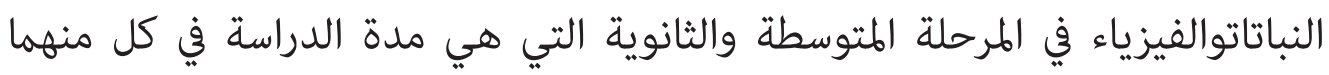

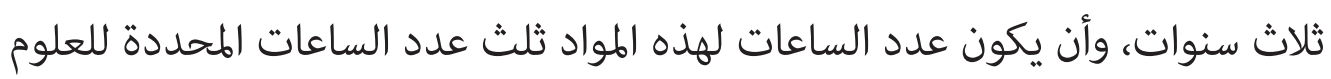

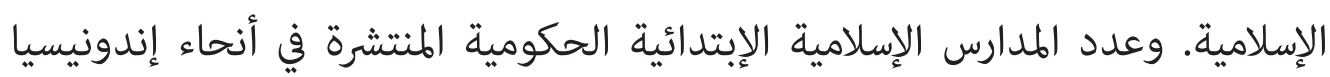
حينئذ مب مدرسة، وبل1 مدرسة متوسطة، و•Vع مدرسة ثانوية.

0 Muhammad Quraish Shihab Dkk, Studi Islamika Indonesien Journal For Islamic, Volume 4, no.2, h. 161-162, Thn 1997 
282 - 292 Burhanuddin \& Triyo Supriyatno, إدارة التعليم في المعاهد والمدارس الإسلامية

\section{ثانيا: المدارس التأهيلية}

لقد كان الهدف من إنشاء المدارس التأهيلية التابعة لوزارة الشؤون الدينية هو الرغبة في تطبيق ما ورد في توصيات الهيئة التنفيذية حول إجراء التربية الدينية في المدارس العامة، وازداد هذا التحفز قوة وثباتا بعد ما صدر القرار المشترك بين وزارة الشؤون الدينية ووزارة التربية والتعليم رقم rع|| التاريخ r ديسمبر سنة 7عا1 م الذي نص على أن يطبق التعليم الديني في المدارس الحكومية العامة اعتبارا من ا يناير Vع اوام، كما أنه يتعين على وزارة الشؤون الدينية أن تغطي النفقات اللازمة لإجراء التعليم الديني وأن تقوم بتعيين المدرسين.

والمدرسة التأهيلية هي عبارة عن مدرسة تؤهل إعداد المدرسين بقسميها العام والإسلامي، وفي ضوء هذا، فقد تم إنشاء المدرسة التأهيلية لإعداد المدرسين الدينيين، ولإعداد قضاة للمحاكم الشرعية بمدينة سولو في تاريخ IV مايو سنة I9 I م. ثم ازدادت الحاجة الملحة إلى فتح أو إنشاء مدارس لإعداد مدرسي العلوم الإسلامية بعد

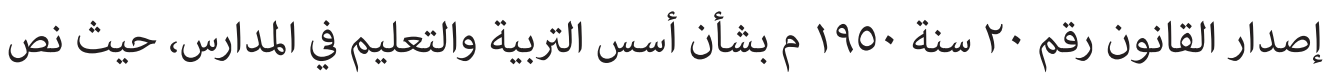
في البندين الأول والثاني من مادة العشرين على أن يجري التعليم الديني في المدارس الحكومية. وفي إطار القيام بفتح مدارس تأهيلية لإعداد مدرسي العلوم الإسلامية، وضعت الحكومية خطتان: ا. الخطة القصيرة المدى وهي عبارة عن إنشاء مدارس تأهيلية لإعداد مدرسي العلوم الإسلامية حيث مدة الدراسة فيها سنتان بعد الحصول على شهادة الثانوية العامة والإسلامية. r. الخطة الطويلة المدى وهي عبارة إنشاء مدارس تأهيلية ومدة الدراسة فيها خمس سنوات بعد الإبتدائية العامة أو الإسلامية.

أما عن عدد هذه المدارس خلال سنة 190 م - -190 م فمجموعها حوالي 9 مع 
ثالثا: مدرسة التأهيل للمعهد العالي الإسلامي قد أنشئت المدرسة سنة ال197 م بناء على قرار وزير الشؤون الدينية رقم 9 سنة 1971 م، ونفس السنة في إنشاء الجامعة الإسلامية الحكومية. وبعد أن كانت هذه المدرسة تقام في يوغياكرتا وحدها سنة المار 197 م، فقد اتسع عددها ليصبح س^ مدرسة في سنة 19VV م. وعندما قت إعادة تشكيل الهيئة والتنظيم للمدارس سنة I9VN تحولت هذه المدرسة إلى المدرسة الإسلامية العالية الحكومية، ثم تحولت إدارتها من إدارة التعليم الإسلامي العالي إلى إدارة التربية الإسلامية. ومن أنواع هذه المدارس تحت إشراف إدارة التربية الإسلامية كما يلي: ا. مدرسة المعلم الديني الحكومية ( PGAN) ومدة الدراسة فيها أربع سنوات، وعددها إم مدرسة، مدرسة

r. المدرسة التأهيلية لإعداد موظفي المحاكم الشرعية، وعددها ثلاث مدارس، س. مدرسة المعلم الديني الحكومية لست سنوات، وعددها 110 مدرسة، ع. مدرسة المعلم الديني الحكومية لست سنوات للبنات، وعددها مدرسة واحدة، 0. المدرسة الإبتدائية التأهيلية لإعداد المعلمين لست سنوات، وعددها سا مدرسة. وبعد إصدار قرار وزير الشؤون الدينية رقم 01، ال، IVI سنة IV9 م يفيد بأنه قد قتت إعادة تشكيل الهيئة والتنظيم للمدارس التابعة لوزارة الشؤون الدينية إلى أربعة أنواع من المدارس وهي المدرسة الإبتدائية الحكومية (MIN)، والمدرسة المتوسطة الحكومية ( MTsN)، والمدرسة الثانوية الحكومية (MAN)، ومدرسة المعلم الديني

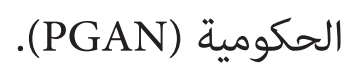


284 - 292 | Burhanuddin \& Triyo Supriyatno, إدارة التعليم في المعاهد والمدارس الإسلامية

ويبين الجدول التالي عدد المدارسج

\begin{tabular}{|c|c|c|c|c|}
\hline 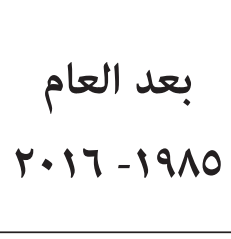 & 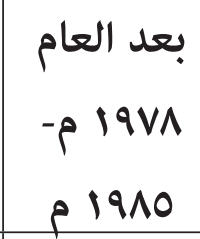 & قبل العام & أنواع المدارس & 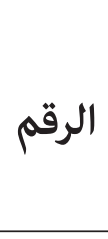 \\
\hline 1774 & rVT & ron & المدرسة الإبتدائية الحكومية & 1 \\
\hline $\mid \mu \wedge \varepsilon$ & or. & 110 & المدرسة المتوسطة الحكومية & $r$ \\
\hline Vro & rTV & ع & المدرسة الثانوية الحكومية & $r$ \\
\hline- & - & $1 \varepsilon 7$ & 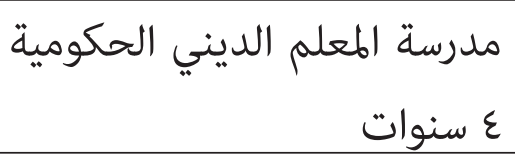 & $\varepsilon$ \\
\hline- & - & 117 & 7 مدرسة المعلم الديني الحكومية & 0 \\
\hline- & q & - & مدرسة المعلم الديني الحكومية & 7 \\
\hline- & - & $r$ & لإعداد القضة التأهيلية الحكومية & V \\
\hline- & - & 1 & مدرسة القضاة الحكومية & $\Lambda$ \\
\hline- & - & $\mu$ & مدرسة التأهيل للمعهد العالي & 9 \\
\hline
\end{tabular}

وحسب الإحصائيات لتطور المدارس الإسلامية الحكومية والأهلية التابعة لوزارة الشؤون الدينية منذ إنشائها إلى سنة 10 •r م في سر محافظة يوضح ذلك في الجدول التالي:

\begin{tabular}{|c|c|c|}
\hline عدد إنشائها إلى سنة 10 • • ب & أنواع المدرسة & الرقم \\
\hline 19, V7r & مدرسة روضة الأطفال & 1 \\
\hline
\end{tabular}




\begin{tabular}{|c|c|c|}
\hline إنشائها إلى سنة المدرسة منذ & أنواع المدرسة & الرقم \\
\hline r1,orq & المدرسة الإبتدائية & $r$ \\
\hline ru,rar & المدرسة المتوسطة & 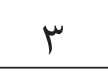 \\
\hline $0,7 \varepsilon \wedge$ & المدرسة الثانوية & $\varepsilon$ \\
\hline
\end{tabular}

المبحث الثالث: مواقف المعاهد والمدارس الإسلامية في إندونيسيا من عصر انفتاح سوق الحرة على مستوى الآسيان

إن مجتمع الآسيان في سياق عصر انفتاح سوق الحرة يواجه الظروف العسيرة والصعبة بما فيها من الهرج أو الاختلافات المضادة والفتن والمعوقات والعقبات والتحديات بكلّ أنواعها وأشكالها، قد لا يوجد مثيلها في القرون الماضية، وهذه التحديات تضطرّ

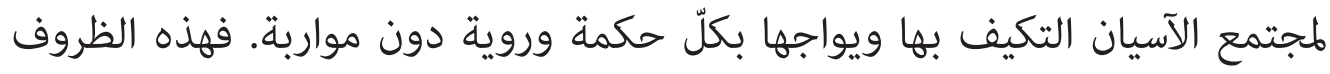
والتحديات تجعل المعاهد والمدارس الإسلامية تختلف وتتعدّد مواقفها تجاهها وكيفية المعايشة مع هذه الملابسات والتحديات. ومن هذه التحديات المتراكمة، تتجلى مواقف المعاهد والمدارس الإسلامية في إندونيسيا في أربعة مواقف رئيسية: الموقف الأول: كان يمثّله الموقف الوسطي، وهذا الموقف أكثر قبولا وإقناعا في معظم المعاهد والمدارس في إندونيسيا، لا يترتب على ذلك جميع التسهيلات والإجراءات والاستفادات بكل يسر دون معاق، وهذا الموقف كان استطاع المعهد أن يواجه الأحداث الموجودة بواقعية ومرونة وحكمة.

الموقف الثاني: يتجلّى ذلك في بعض المعاهد والمدارس المنغلقة عن المحارسات الاقتصادية والانشغالات الدنيوية، حيث يركز المعهد على التعاليم الروحية وعدم المواكبة عن واقع الحياة وعن مستجدات العصر. 
286 - 292 | Burhanuddin \& Triyo Supriyatno, إدارة التعليم في المعاهد والمدارس الإسلامية

الموقف الثالث: أن المعهد يتنحى ويبعد عن القضايا التي تسّّ واقع حياة المجتمع واتحاد الأمة الإسلامية بأجمعها والسياسية، ونجد ذلك في كثير من المعاهد والمدارس الإسلامية في إندونيسيا بأنّها لا تقبل الانفتاح الوعي على ثقافات الآخرين. الموقف الرابع: خطاب الرفض والاحتجاج، وهذا عدد ضئيل جدا. والسبب في ذلك يرجع إلى فهم أمناء المعهد السطحي عن إدارة المعهد وأنظمته وعن رؤيته ورسالته المستقبلية.

المبحث الرابع: المعاهد والمدارس الإسلامية ودورها في تعزيز الرحمة نحو السلام العالمي إن للمعاهد والمدارس الإسلامية في أوساط المجتمع الطسلم الإندونيسي منزلة فذة ومرموقة وسامية توجب عليها من المهام ما لا يجب على غيرها من الأنظمة السياسية. ومن أبرز وأظهر دور المعاهد والمدارس الإسلامية في إندونيسيا في ظل التطورات الراهنة هي البيان، إذ أنه بمثابة وظائف العلماء ورثة الأنبياء، مصداقا لقوله تعالى:\}َوَإِذْ أَخَذَ

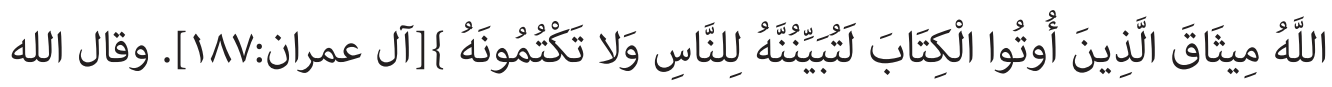

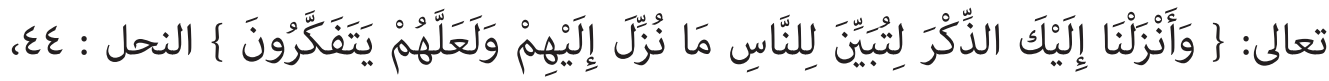

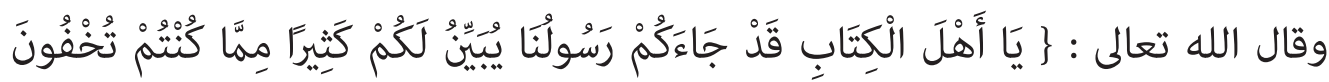

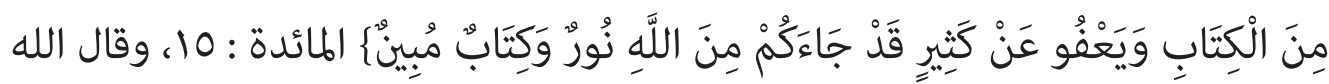

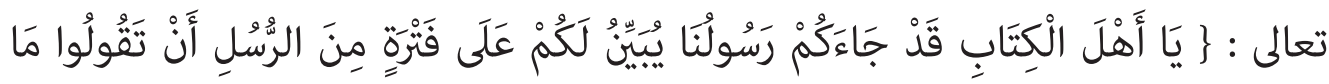

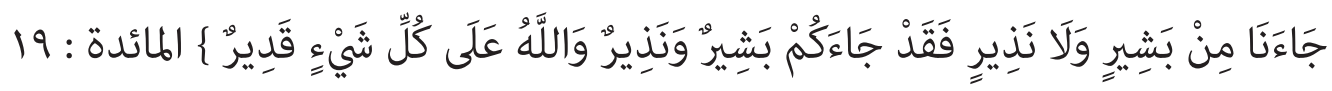
ويشمل ذلك البيان: البيان التأصيلي وذلك بعرض الحق، وتعليم الناس السنة وهدايتهم إلى الصراط المستقيم. والبيان التحصيني وذلك بالتحذير من الانحرافات والأهواء والضلالات، ورد الشبهات. والبيان العلاجي وذلك بَعالجة ما وقع من مشكلات، والإفتاء فيها، وبيان سبل الخلاص منها. 
ومندورها أيضا نشر رحمة الله للعالمين، وقدقال الله تعالى: \}َوَمَا أَرَسَلْنَاكَ إِلَّا

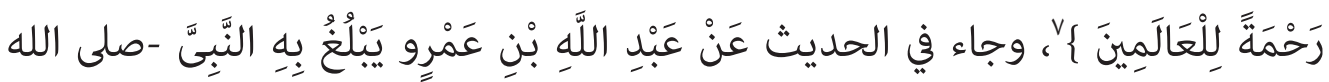

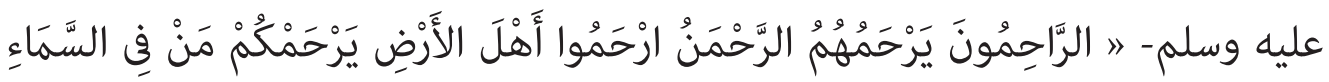

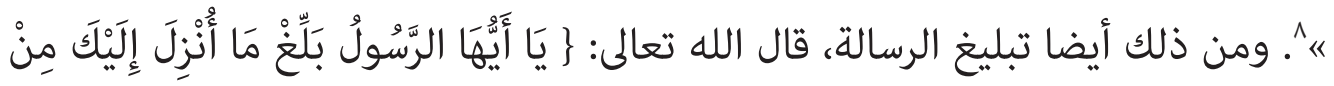

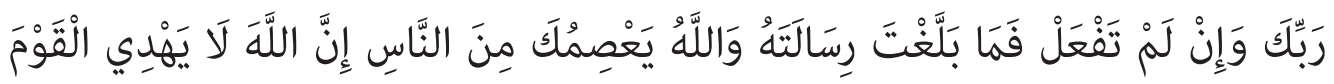

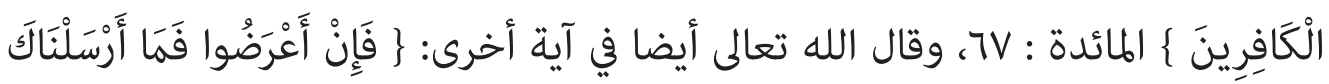

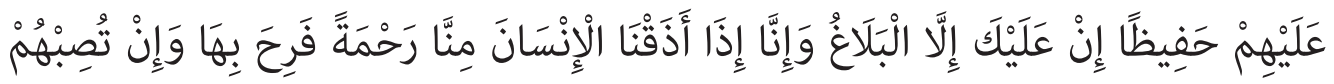

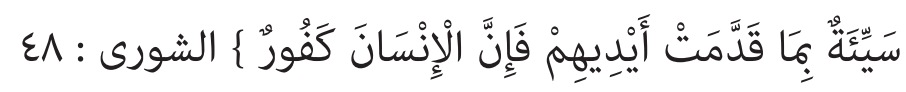

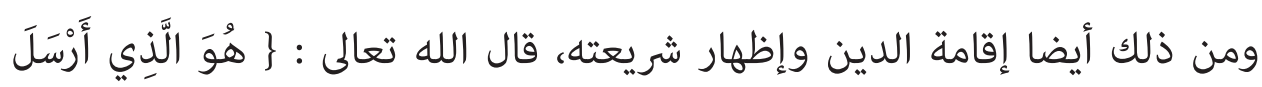

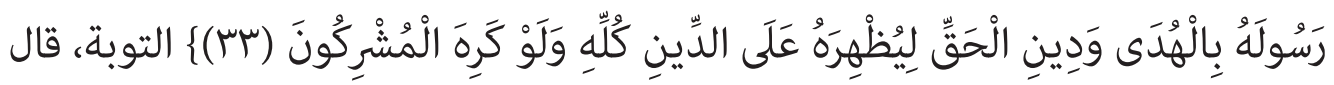

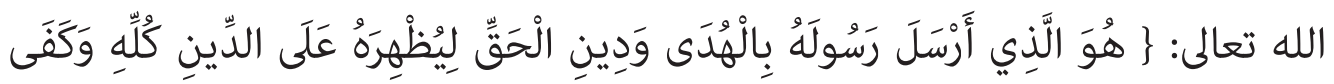

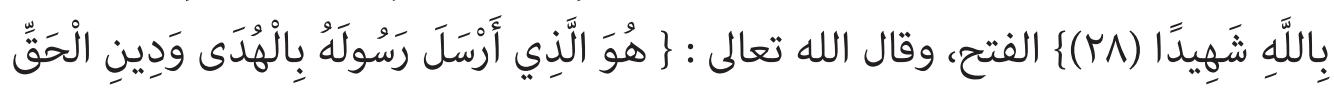

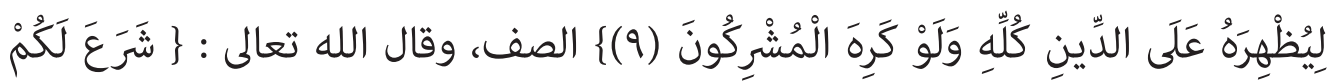

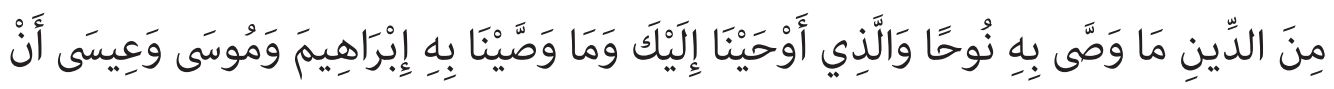

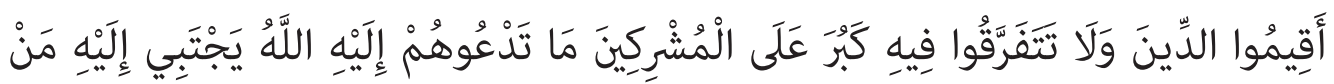

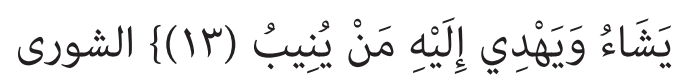

انطلاقاما سبق، يتلخص أن من أهم دورامعاهد والمدارس الإسلامية في إندونيسيا في تعزيز الرحمة العالية وتحقيق السلام العالمي في ظل الآونة الراهنة ما يلي: أولا: تبليغ الناس بغاية الشريعة الإسلامية السمحة والوسطية أفرادا ومجتمعات، لئل

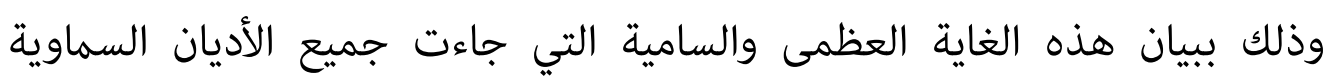

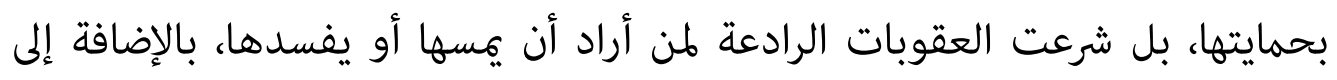

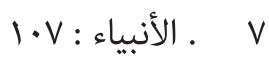

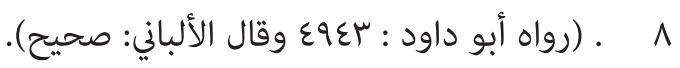


288 - 292 Burhanuddin \& Triyo Supriyatno, إدارة التعليم في المعاهد والمدارس الإسلامية

لفت أنظار الناس إلى جوانبها المتمثلة في حفظ مصلحة الفرد والمجتمعالخمسة:حفظ الدين، وحفظ النفس، وحفظ العقل، وحفظ النسل، وحفظ المالج ـ علما بأن الشريعة الإسلامية الخالدة جاءت متلائة مع فطرة الإنسان، وحاجاته الحقيقية، متسمة بالوسطية والاعتدال، وبالمثالية الواقعية، خالية من كل حرج، وإعنات، قال تعالى : (يريد الله بكم اليسر”' ولا يريد بكم العسر) ("') وقال جل شأنه : ( وما جعل عليكم في الدين من حرج ) ("ا") وقال عليه الصلاة والسلام : " بعثت بالحنفية السمحة ٪ ("آ) . وبهذا، اتضح بأن الشريعة الإسلامية الغراء توصف بهرونة ديناميكية حيوية، واهتمامها البالغ بجميع الحالات والظروف التي يمكن أن تعتري المسلم في حياته اليومية في أيّ مجال من مجالات حياته.

ثانيا: توجيه أفراد الهجتمع للمحافظة على هويتهم وانتهائهم لعقيدتهم وقيمهم ووطنهم؛ لأن هذا الانتماء يعيد حياة الفرد في ضميره الذي يشكل أهم أبعاد شخصيته، كما أنه يعيد حياة الفرد في الدولة التي يعيش فيها، ويقوم بدور مهم في جديته في العمل من أجل إثبات استحقاق نعمة العيش في ظلالها ـ لذا يككن المحافظة على الهوية والانتماء من خلال عدة أساليب ترتبط ارتباطاً وثيقًا بتنمية ركائز الشخصية وذلك

انظر: المستصفى، الغزالي، ج)، ط القاهرة: المكتبة التجارية الكبرى، الكمباه، صMMr ـ والموافقات،

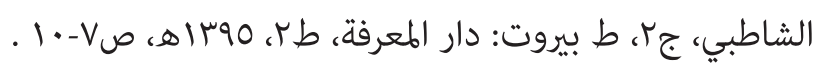

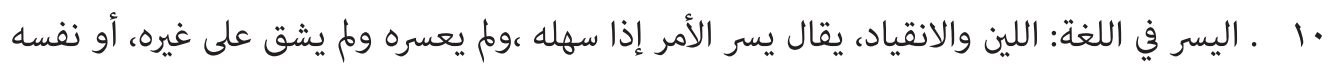

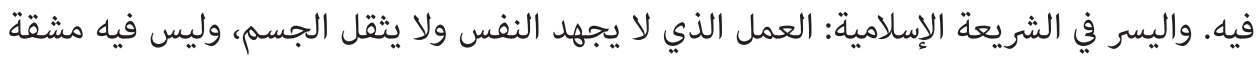
زائدة ويقابله قاما العسر؛ لأن هذا فيه إجهاد للنفس، وفيه ضرر للجسم، وفيه مشقة زائدة. انظر:

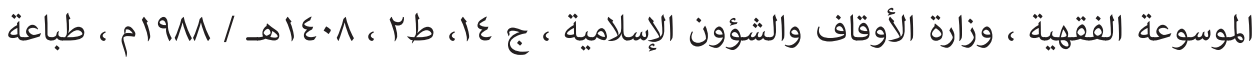

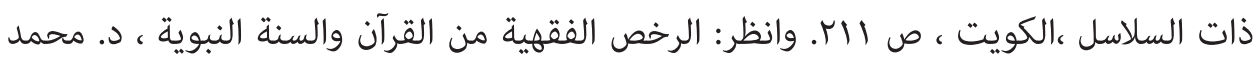

$$
\begin{aligned}
& \text { الشريف الرحموني ، ص: 7سا. } \\
& 111 \text { - البقرة / 110 . }
\end{aligned}
$$

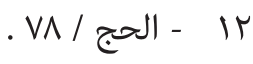

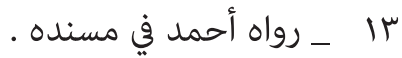


بالتوجيه الديني الوسطي عا والتوجيه الاجتماعي وهو نوع من تنمية جوانب الشخصية

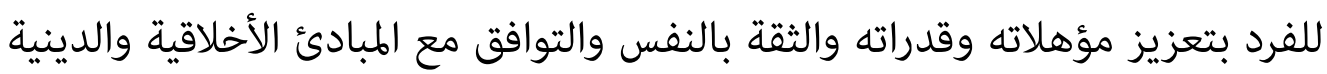

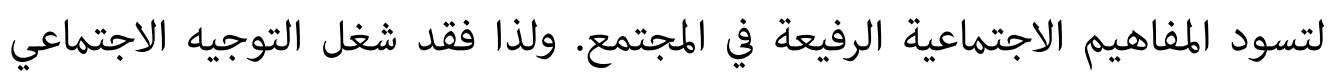

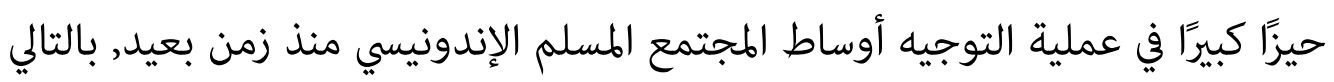

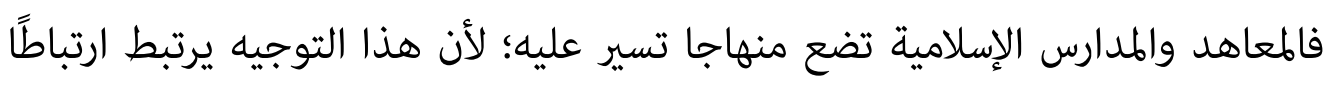

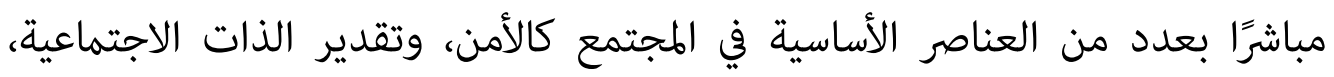
والانتماء، والتماسك الاجتماعي.

ولعل من أبرز ما يستهدفه التوجيه الاجتماعي دعم الانتماء الوطني، وذلك أن أن إنهاء

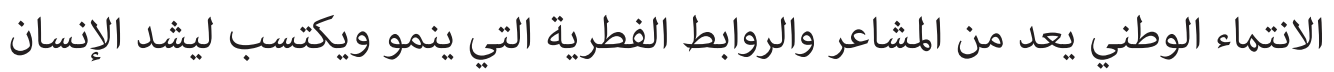

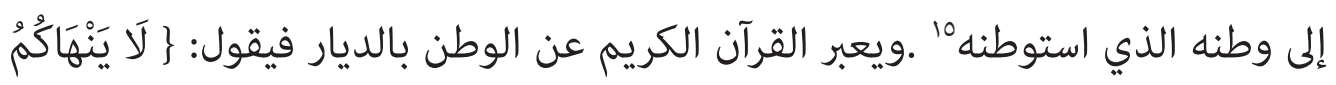

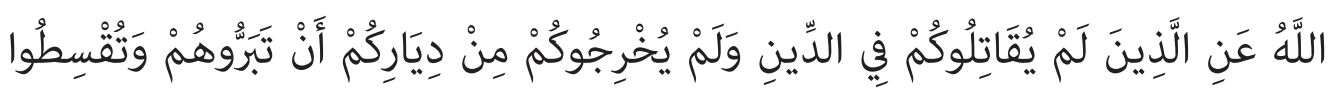

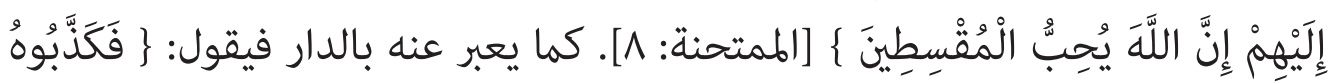

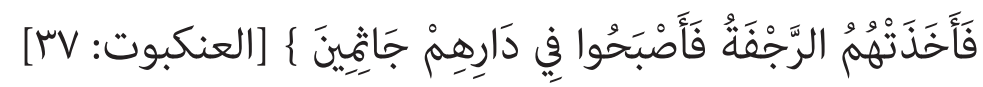

وبهذا، يجعل أفراد المجتمع يتكاتفون على احترام النظام ومراعاة الحقوق،

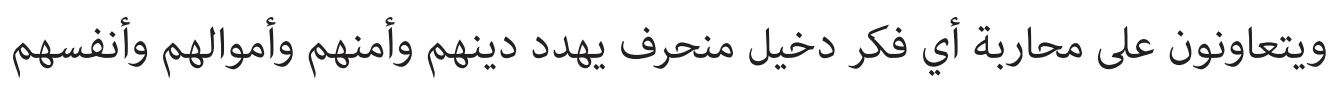

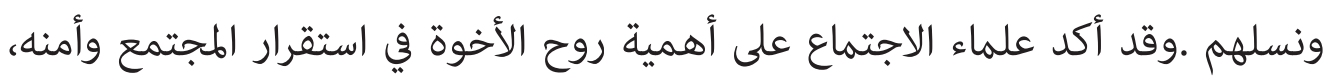

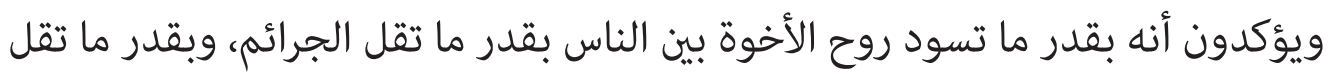

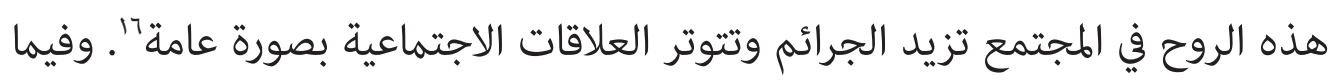

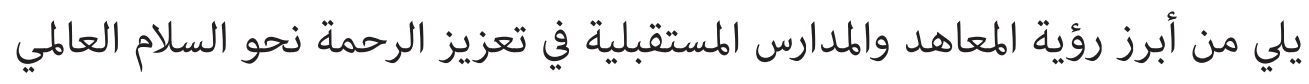

عا انظر: الحفاظ على الهوية الإسلامية، محمد شحات الخطيب، طا، جامعة الإمام محمد بن سعود

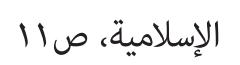

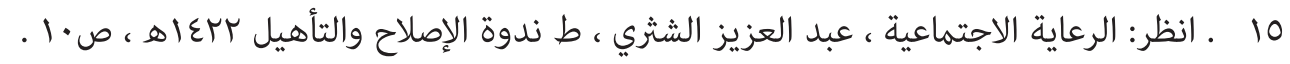

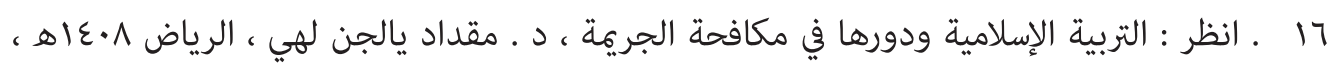


290 - 292 Burhanuddin \& Triyo Supriyatno, إدارة التعليم في المعاهد والمدارس الإسلامية

ا. ضرورة إدراك الأمة الإسلامية لأهمية حفظ السلام وتعزيزه على أسس التسامح، واحترام حقوق الإنسان، والطساواة، والاحترام المتبادل، والعدالة، ووحدة الأمة والتعاون والتحاور بين الحضارات.

r. دعم الحوارات الفعالة بين العلماء المسلمين والمفكرين، ورجال القانون، وواضعي السياسات، وبين المؤسسات التي ينتمون إليها من أجل المساهمة في تحقيق السلام العاليي، والسد من الصراعات والخلافات، مع تعزيز الوحدة والترابط بين الأمة

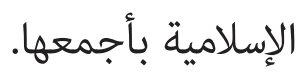

س. تأكيد مشاريع الحوار المتكافئ بين الثقافات والحضارات من خلال المنظمات الإقليمية والدولية من أجل تعزيز التفاهم المشترك مع نشر القيم الإسلامية كدين بين

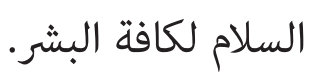
ع. تعزيز شعار الإسلام الوسطي والرحمة للعالمين 0. إنشاء لجان السلام والتنمية المستدامة في المجال الاقتصادي والتربوي والاجتماعي والثقافي والإعلامي وغيرها من أدوات سبل التحقيق السلام العالمي.

\section{نهاذج من تجربة المعاهد والمدارس في نشر الخطاب الإسلامي الوسطي}

إن الحديث عن المدارس والكعاهد في إندونيسيا في نشر الخطاب الإسلامي الوسطي يتميز منهجها بخطاب الوسطية الإسلامية، وبهذا المنهج استطاعت أن تجمع بين الأصالة والحداثة وتواجه الظروف والتحديات المعاصرة التي قد لا يوجد مثيلها في القرون الماضية والتكيف بكل أنواعها بواقعية ومرونة وحكمة وصبر.

واتضح أن من الأهداف الرئيسة لإنشاء المدارس والطعاهد كلّها تهدف إلى هدف واحد وهو تحقيق بناء الشخصية الإسلامية بين أوساط المجتمع المسلم وانبعاث الصحوة الإسلامية الوسطية على أراضي الأرخبيل الأندونيسي ولتربية المسلمين بتعاليم إسلامية وسطية منصفة، وبأن تكون أكثر فعالة لدى الأمة الإسلامية ولحمايتهم عن التحديات 
الخارجية المتمثلة في التيارات المنحرفة. ولذلك حاولت أن تقوم بنشر الدعوة الإسلامية بالمنهج الوسطي المعتدل المنصف القائم على التسامح والعدل والخيري في إندونيسيا في

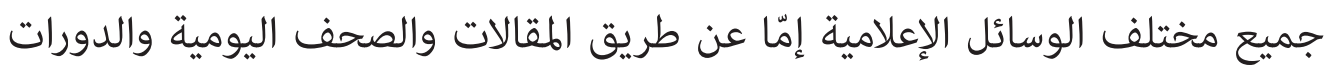

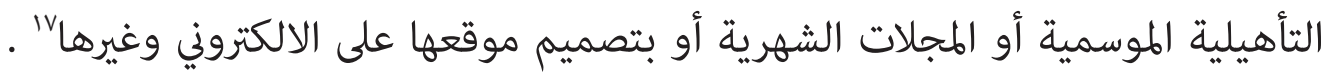
ومن ثم، نهجت تلك المدارس والمعاهد في نشر الخطاب الإسلامي بمنهج الوسطية وهو

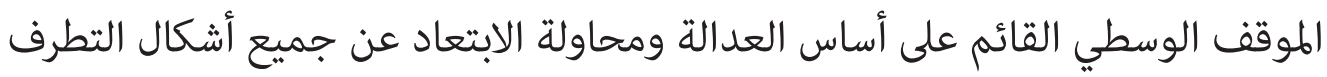
والغلو. بالإضافة إلى بث التسامح وهو الموقف الوسطي القائم الماسم على أساس احترام الآراء المختلفة والحضارات المتعددة الموجودة في المجتمع، وإلى جانب التوازن وهو الموقف

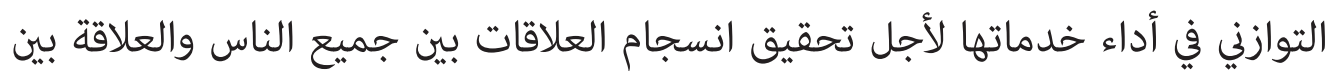

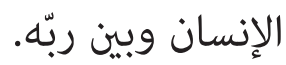

وبهذا، استطاعت التأثير وإقناع المجتمع الإندونيسي بسبب الأساليب والمناهج

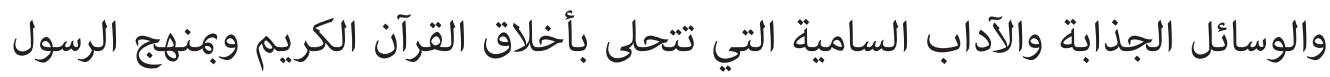

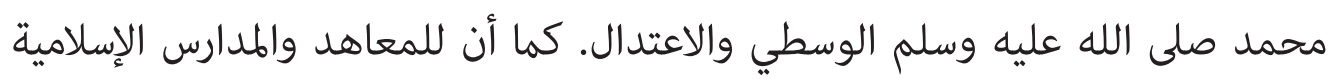

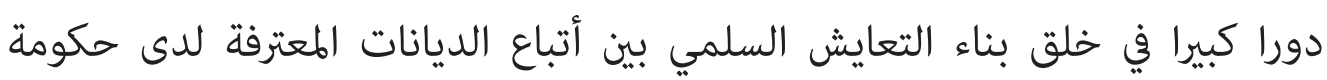

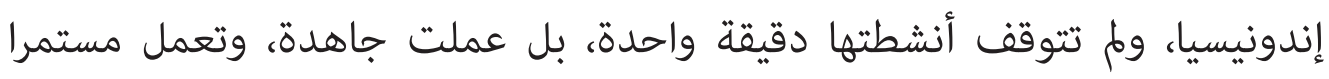

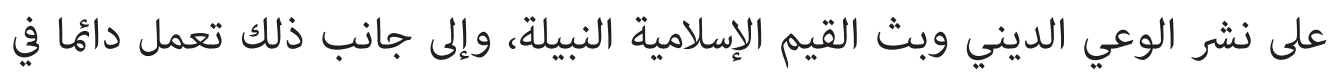

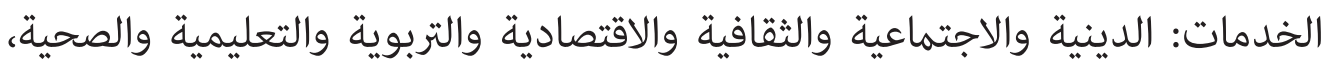

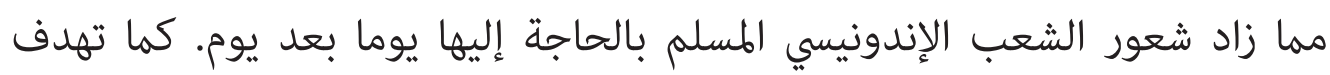

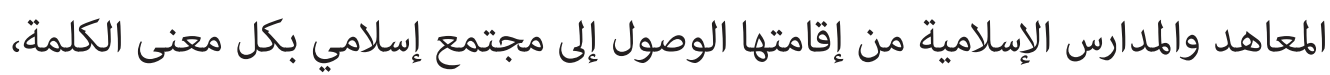
وهو مجتمع يسوده الأمن والتقدم والازدهار والعدل والسعادة في الدارين.

قائمة المصادر والمراجع باللغة الإندونيسية

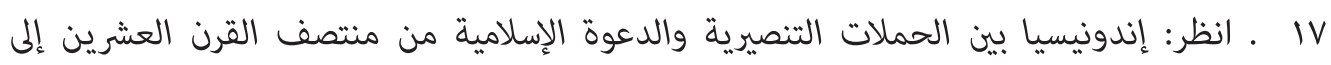
أواخره، محمد ريحان ناسوتيون، ص 190 
1. Muhammad Qurais Shihab MA. Dkk, Studia Islamika Indonesian Journal For Islamic Studies, volume8, Number 1, Thn $2001 \mathrm{M}$.

2. Muhammad Qurais Shihab MA. Dkk, Studia Islamika Indonesian Journal For Islamic Studies, volume2, Number 4, Thn 1995 M.

3. Muhammad Qurais Shihab MA. Dkk, Studia Islamika Indonesian Journal For Islamic Studies, volume 7, Number 1, Thn $1998 \mathrm{M}$.

4. Muhammad Qurais Shihab MA. Dkk, Studia Islamika Indonesian Journal For Islamic Studies, volume 2, Number 2, Thn 1995 M.

5. Muhammad Qurais Shihab MA. Dkk, Studia Islamika Indonesian Journal For Islamic Studies, volume 8, Number 2, Thn $2001 \mathrm{M}$.

6. Muhammad Qurais Shihab MA. Dkk, Studia Islamika Indonesian Journal For Islamic Studies, volume 1, Number 3, Thn 1994.

7. Muhammad Qurais Shihab MA. Dkk, Studia Islamika Indonesian Journal For Islamic Studies, volume 3, Number 2, Thn $1996 \mathrm{M}$.

8. Muhammad Qurais Shihab MA. Dkk, Studia Islamika Indonesian Journal For Islamic Studies, volume 9, Number 3, Thn $2001 \mathrm{M}$. 